\title{
Pandemia pela Covid-19 e multilateralismo: reflexões a meio do caminho
}

\author{
PAULO M. BUSS, I SANTIAGO ALCÁZAR II \\ e LUIZ AUGUSTO GALVÃO ${ }^{I I I}$
}

\section{Introdução}

A

PANDEMIA provocada pelo Sars-CoV-2, o novo coronavírus, não foi, absolutamente, uma surpresa para os sanitaristas e epidemiologistas. O High-Level Panel on the Global Response to Health Crises (Unga, 2016a), criado em abril de 2015 pelo secretário-geral das Nações Unidas, Ban Ki-moon, para examinar e extrair lições da epidemia pelo vírus ebola, que entre 2013 e 2016 afetou a África Ocidental - principalmente três países: Libéria, Sierra Leoa e Guiné - mas ameaçava espalhar-se pelo mundo, ${ }^{1}$ já previa a ocorrência de pandemias em anos vindouros. Em informe que somou 97 páginas, 248 parágrafos e 27 grandes recomendações, em diversas dimensões, e que foram assumidas pela Assembleia Geral da ONU, o Panel recomendou a realização de uma cúpula mundial sobre crise global em saúde pública, em 2018, com a participação das mais altas autoridades dos Estados-membros, para preparar o sistema multilateral e cada país para futuras ameaças à segurança humana representadas por enfermidades epidêmicas.

Tivesse o sistema multilateral se organizado e os governos dos Estados-membros atendido as recomendações multidimensionais relativas às epidemias estaríamos agora submetidos ao pesadelo da Covid-19?

A verdade é que vivemos uma crise do sistema multilateral, aos 75 anos de criação da ONU que se comemorarão (?) este ano. Atacada por seu gigantismo e ineficiência, quer queiram, quer não os governos de certos Estados-membros, a ONU continua sendo o mais importante espaço de discussão e acordos globais existente. No campo da saúde internacional, por sua vez, esse papel é desempenhado pela Organização Mundial da Saúde (OMS). Coerente com essa missão, em 2005, a 58 a Assembleia Mundial da Saúde - que reúne anualmente todos os ministros da saúde dos Estados-membro da organização - aprovou uma regulamentação seminal, o Regulamento Sanitário Internacional (RSI), para entrar em vigor mundialmente em 2007, visando "prevenir, proteger, controlar e dar respostas de saúde pública contra a propagação internacional de doenças, de maneiras proporcionais e restritas aos riscos para a saúde pública [...]" (Anvisa, 2005). 
Em 31 de dezembro de 2019, a OMS foi alertada sobre vários casos de pneumonia na cidade de Wuhan, província de Hubei, na República Popular da China. Uma semana depois, em 7 de janeiro de 2020, as autoridades chinesas confirmaram que haviam identificado um novo tipo de coronavírus, não encontrado antes em seres humanos. Coronavírus estão amplamente distribuídos na natureza e são a segunda principal causa de resfriado comum (após os rinovírus) $\mathrm{e}$, até as últimas décadas, raramente causavam doenças mais graves em humanos.

Ao todo, sete coronavírus humanos (HCoVs) já foram identificados: HCoV-229E, HCoV-OC43, HCoV-NL63, HCoV-HKUl, Sars-COV (que causa síndrome respiratória aguda grave), Mers-COV (que causa síndrome respiratória do Oriente Médio) e, o mais recente, o novo coronavírus (que no início foi temporariamente nomeado 2019-nCoV e, em 11 de fevereiro de 2020, recebeu o nome de Sars-CoV-2). Ele é responsável por causar a doença Covid-19.

Em 30 de janeiro de 2020, o diretor-geral da OMS, Tedros Adhanom, declarou a Covid-19 como Emergência de Saúde Pública de Importância Internacional (ESPII), em conformidade com os critérios e procedimentos estabelecidos no RSI, o mais alto nível de alerta emitido pela Organização. É a sexta vez na história que uma ESPII é declarada. ${ }^{2}$ Em 11 de março de 2020, a Covid-19 foi caracterizada pela OMS como uma pandemia.

Até 10 de junho de 2020, tinham sido confirmados no mundo mais de 7 milhões de casos e mais de 400 mil mortes por Covid-19. Nem uma outra enfermidade transmissível viral produziu tamanho número de casos e óbitos, em tão curto espaço de tempo, nos últimos 100 anos da história da saúde mundial. ${ }^{3}$

Este artigo examina, de forma preliminar, a resposta do sistema multilateral das Nações Unidas à pandemia pela Covid-19, com foco na Secretaria Geral (SG), Assembleia das Nações Unidas (AGNU) e na agência especializada em saúde, a Organização Mundial da Saúde (OMS) e seu braço hemisférico, a Organização Pan-americana da Saúde (Opas), do início da pandemia, ao redor de janeiro de 2020, até o final do mês de maio do mesmo ano.

A metodologia utilizada foi identificar e analisar os principais textos produzidos no âmbito do sistema multilateral, vale dizer suas resoluções, documentos básicos e declarações referentes ao tema da pandemia pela Covid-19, destacando e comentando criticamente suas principais conclusões.

\section{Resposta das Nações Unidas}

Antes da Covid-19, a Assembleia Geral das Nações Unidas (AGNU), órgão de máxima decisão política da Organização, tratou de temas da saúde em apenas quatro ocasiões, todas neste século. Na primeira, em maio de 2001, a AGNU convocou sessão especial para tratar da questão HIV/Aids. À época, estimava-se que 33 milhões de pessoas estavam infectadas e 14 milhões haviam falecido desde o início da epidemia. A economia global apresentava índices de crescimento pouco superior a $1 \%$. O HIV/Aids preocupava pelos números, mas 
a economia global não parecia afetada. O baixo desempenho era função de fatores que nada tinham a ver com a pandemia.

A segunda aconteceu em 2010, quando adotou a resolução (A/RES/ 64/265) (Unga, 2010), pela qual solicitava a realização de Reunião de Alto Nível, no quadro da próxima AGNU, para examinar a questão da prevenção e controle das Doenças Crônicas Não Transmissíveis (DCNT), de que são exemplo as doenças cardiovasculares, hipertensão, diabetes e neoplasias. Segundo dados disponíveis, as DCNT respondiam pela morte de 36 milhões de pessoas por ano. A economia global, em fase de recuperação da crise financeira de 2007/2008, apresentava índices animadores.

$\mathrm{Na} 65^{\text {a }}$ AGNU (2010), pela terceira vez um tema da saúde seria considerado pela Assembleia Geral, que adotou resolução intitulada Global health and foreign policy (A/RES/65/95) (Unga, 2011), que retomava Declaração do mesmo nome concluída por sete ministros de negócios estrangeiros em Oslo, em 2007 (The Lancet, 2007). A importância daquela Declaração reside no reconhecimento, por parte de ministros oriundos de outra pasta, de que ameaças à saúde podem comprometer a estabilidade e a segurança de um país e de que, portanto, acordam fazer do impacto à saúde um ponto de partida e uma lente através da qual passarão a ser examinadas políticas e estratégias de desenvolvimento. No debate geral, várias delegações recordaram o amplo leque de interação entre a saúde global e a sua política exterior: a luta contra a pobreza e a busca da paz e da segurança, mas também, e très à propos para a atual circunstância, a combinação de esforços para combater doenças transmissíveis e pandemias. A relação entre as duas áreas foi assim consolidada e o tema passou a fazer parte da agenda da AGNU com o reconhecimento posterior de que os seres humanos estão no centro das preocupações com desenvolvimento sustentável e são merecedores de uma vida saudável e produtiva em harmonia com a natureza.

É de notar também que aquela resolução reafirmava, em parágrafo preambular, o direito a utilizar plenamente as disposições de TRIPS e a Declaração de Doha sobre TRIPS e Saúde Pública, de modo a promover o acesso universal a medicamentos. Duas observações: i) o advérbio não deixa dúvida sobre o direito de flexibilizar o Acordo de modo a atender a necessidades de saúde pública; este ponto será importante quando fizermos menção às resoluções adotadas pela AGNU e pela OMS com respeito à Covid-19; ii) a redação do parágrafo faz referência apenas a medicamentos, tendo presente certamente o problema de saúde pública decorrente sobretudo do HIV/Aids. É importante sublinhar, no entanto, que o Acordo de TRIPS não se refere apenas a medicamentos, mas a todo o conjunto de produtos que podem ser necessários no tratamento de uma emergência sanitária, inclusive os seus componentes e precursores, que também podem estar protegidos por regime de patentes.

A quarta vez que a AGNU tratou de um tema de saúde foi por causa do surgimento do vírus ebola, na África Ocidental, durante a realização de sua 
69 ${ }^{\text {a }}$ sessão, em 2014. Naquele ano, a Assembleia adotou resolução intitulada Medidas para conter e combater o recente surto de Ebola na África Ocidental (A/ RES/69/1) (Unga, 2014), pela qual, preocupada com os efeitos devastadores daquele vírus, acolhia com beneplácito a iniciativa do secretário-geral de estabelecer, pela primeira vez na história da Organização, uma missão das Nações Unidas para formular resposta de emergência a determinada enfermidade. No ano seguinte, em 2015, durante a $70^{\text {a }}$ AGNU, o secretário-geral, após considerar o informe da missão e com o agravamento da crise sanitária, decidiu estabelecer o High-level Panel (HLP) on the Global Response to Health Crisis. O HLP apresentou relatório, em 9 de fevereiro, de 2016, com o título Protecting humanity from future health crises - Report of the High-level panel on the Global Response to Health Crises (Unga, 2016a). Como curiosidade, deve-se registrar que a consideração do relatório pela $70^{\text {a }}$ AGNU foi incluído sob o item 125 da agenda (Unga, 2016b), sob o tema Saúde Global e Política Exterior. A lente da saúde da Declaração de Oslo tornara-se uma realidade no âmbito das Nações Unidas.

O relatório do HLP é um documento de 96 páginas, que contém 27 recomendações para ação nos níveis nacional, regional e internacional, incluindo medidas de alcance transversal que demandam engajamento de todos os setores dos governos e das sociedades. Entre as recomendações caberia registrar, entre outras, as seguintes: i) países devem aumentar a capacitação de profissionais de saúde; ii) organizações regionais e sub-regionais devem fortalecer suas respectivas capacidades de monitoramento, prevenção e resposta; iii) a OMS deve fortalecer sua liderança e estabelecer capacidade operacional eficaz e unificada; iv) a comunidade internacional deve cumprir seu compromisso com respeito aos ODS, com ênfase naqueles relacionados à saúde; v) os Estados-membros da OMS devem aumentar suas contribuições mandatórias àquela Organização em pelo menos 10\%; vi) a AGNU deve criar imediatamente conselho de alto nível sobre crises na saúde pública global, de modo a garantir que o mundo estará preparado para tais crises; vii) convocar reunião de cúpula, em 2018, focada na preparação e resposta à crises sanitárias.

O conselho de alto nível acabou virando uma força tarefa, estabelecida pelo secretário-geral Ban Ki-moon, com o título Global Health Crises Task Force. $\mathrm{O}$ mandato da força tarefa estender-se-ia pelo período de um ano, com início em $1^{\circ}$ de julho de 2016. O objetivo da força tarefa era certificar-se da efetiva implementação das recomendações do HLP. A Força Tarefa foi copresidida por Amina Mohammed, vice-secretária-geral da ONU, Margareth Chan, diretora-geral da OMS e Jim Yong Kim, presidente do Banco Mundial.

Em 2017, a 72 ${ }^{\text {a }}$ Sessão da AGNU adotou a resolução A/RES/72/139 (Unga, 2018), intitulada Global health and foreing policy: addresing the health of the most vulnerable for an inclusive society. No quarto parágrafo operativo, a Assembleia nota com apreço o trabalho da Força Tarefa e solicita ao secretário-geral atualizações periódicas sobre a implementação das recomendações. No 
parágrafo operativo 23, acolhe a convocação por parte da OMS de Conferência Global sobre doenças não transmissíveis, como preparação para a reunião de cúpula da Assembleia Geral sobre revisão e avaliação do progresso alcançado na prevenção e controle dessas doenças. Em 2017, tanto a diretora-geral da OMS, Margareth Chan, quanto o secretário-geral da ONU, Ban Ki-moo, terminaram os seus respectivos mandatos. Em seus lugares assumiram Tedros Adhanom e Antonio Guterres, respectivamente.

É evidente que a ameaça do ebola já parecia distante em 2017. O relatório da Força Tarefa havia perdido interesse e encontrava-se órfão na agenda da AGNU. Teve de ser acolhido pelo tema saúde global e politica exterior, de maneira adjetiva. A reunião de cúpula, recomendada pelo HLP, teve seu papel reduzido à prevenção e controle de doenças não transmissíveis e não mais a de preparação e resposta a crises sanitárias. De qualquer maneira, não foi convocada até o presente. O desempenho da economia no biênio $2017 / 2018$ era positivo, com taxas de crescimento acima do esperado.

Em 2020, a Covid-19 obrigou as Nações Unidas a retomar o assunto das emergências sanitárias, desta vez com atenção quase exclusiva.

A sequência de eventos da pandemia pelo novo coronavirus é bem conhecida. Para este artigo, basta recordar algumas datas significativas:

- 31 de dezembro de 2019, China comunica OMS sobre casos de pneumonias atípicas

- 7 de janeiro de 2020, autoridades chinesas confirmam identificação de um novo tipo de coronavírus

- 11 de janeiro, primeira morte em Wuhan

- 20 de janeiro, terceira morte e mais de 200 infectados

- 25 de janeiro, total de 41 óbitos e 1.297 casos na China, e 23 fora da China

- 4 de fevereiro, número de óbitos supera 800 pessoas, já maior do que as vítimas pela Sars

- 12 de março, desde o início da epidemia há mais de 4.700 mortos e mais de 128 mil casos.

Na manhã de segunda-feira, dia 9 de março, o índice da S\&P 500 caiu 7\% em apenas 4 minutos. Um algoritmo (circuit breaker) interrompeu as negociações em bolsa, pela primeira vez desde a crise financeira de 2007/2008. Em 11 de março, a OMS declara o surto da Covid-19 uma pandemia. O circuit breaker seria acionado de novo nos dias 12 e 16 de março. As perdas de valores em bolsa deixavam para trás a casa de bilhões e afirmavam-se na casa de trilhões de dólares em todo o mundo. Já não mais se tratava de uma doença transmissível confinada em algum canto do mundo ou de uma epidemia como o HIV/Aids que, embora tivesse impacto sobre a economia, nunca a ameaçou com paralisia. Agora tratava-se de um novo vírus que sufocava as pessoas e paralisava a economia, de- 
vido às medidas de distanciamento social, confinamento, quarentena e lockdown, recomendadas como únicas defesas contra a contaminação pelo microrganismo.

Nesse contexto, o secretário-geral Antonio Guterres fez, em 11 de março, o primeiro de uma série de pronunciamentos sobre a crise sanitária. Naquela ocasião disse: "Vamos superar isto juntos!", sem ter ainda clareza quanto à real dimensão do problema. Em 19 de março, Guterres dizia que estávamos enfrentando uma crise nunca antes experimentada nos 75 anos da Organização. "Uma recessão de dimensão recorde é quase uma certeza. Estamos em uma situação sem precedentes. As regras normais não mais se aplicam. Não é mais possível recorrer aos instrumentos de sempre para estes tempos tão pouco normais".

Em 23 de março, SG anuncia o lançamento de um plano de resposta humanitária global para auxiliar no combate à pandemia nos países mais pobres. O plano, coordenado pelo Escritório das Nações Unidas para a Coordenação de Assuntos Humanitários (Unocha, em seu acrônimo em inglês) (Unocha, 2020a), envolve a OMS, bem como outras agências do sistema.

Em 31 de março, o secretário-geral anuncia o lançamento do relatório Shared Responsibility, Global Solidarity: Responding to the sócio-economic impacts of Covid-19 (UN, 2020a). O relatório faz um chamamento para uma resposta multilateral coordenada de grande escala, capaz de arrecadar $10 \%$ do PIB mundial. Paralelamente, o sistema todo das Nações Unidas passa a trabalhar com os governos na resposta à pandemia, bem como na recuperação das economias.

Ademais, o secretário-geral estabeleceu o The Secretary-General's UN Covid-19 Response and Recovery Fund (UN, 2020b), com o objetivo de auxiliar países de renda baixa e média, que complementa o Strategic Preparedness and Response Plan (WHO, 2020a) da OMS, atualizado em 14 de abril, bem como o Consolidated Global Humanitarian Appeal for Covid-19 (Unocha, 2020a; $2020 b$ ) da Unocha. Na apresentação das duas iniciativas, Antonio Guterres foi enfático: "Podemos voltar ao mundo de antes ou enfrentar as questões que nos fizeram desnecessariamente vulneráveis a crises. $\mathrm{O}$ nosso mapa aponta para a Agenda 2030 e os 17 ODS. A recuperação da COVID-19 deve levar-nos a uma economia diferente". Em 23 de abril, em novo pronunciamento, o SG anuncia o lançamento do relatório Covid-19 and Human Rights: we are all in this together (UN, 2020c), no qual reitera a centralidade das pessoas em meio à pandemia.

Em 24 de abril, o SG participou do lançamento virtual de iniciativa de alguns chefes de Estado ou de Governo e lideranças na área da saúde global, de manifestar compromisso para juntos trabalhar para acelerar o desenvolvimento e a produção de vacinas novas, testes de diagnóstico e tratamentos para a Covid-19, bem como para garantir o acesso equitativo em todo o mundo. Em sua fala, o secretário-geral recordou que a Covid-19 estava a precisar apoio à saúde pública sem precedente. "Não uma vacina ou tratamento para um país, uma região ou a metade do mundo, mas uma vacina e tratamento para todos, em todo o mundo." Os produtos que resultarão da iniciativa Access to Covid-19 Tools 
Accelerator (ACT) (WHO, 2020b), como acabou sendo conhecida a iniciativa, "devem ser exemplo essenciais de bens públicos globais", afirmou Guterres naquela ocasião. O próprio documento declara que "nossa missão não é apenas o desenvolvimento acelerado e a disponibilidade de novas ferramentas Covid-19 - é acelerar o acesso global equitativo a diagnósticos, terapêuticas e vacinas Covid-19 seguras, de qualidade, eficazes e acessíveis, e assim garantir que na luta contra Covid-19, ninguém é deixado para trás".

Em 18 de maio, o SG dirigiu-se virtualmente à $73^{\mathrm{a}}$ Assembleia Mundial da Saúde. Em sua mensagem, Antonio Guterres declarou que "uma vez virada a página da Covid-19, será preciso olhar no retrovisor e procurar entender como surgiu esta pandemia e como reagiram os envolvidos. As lições aprendidas se mostrarão essenciais para os desafios futuros". A reflexão do SG parece ecoar as recomendações do HLP, que não mereceram a atenção devida.

Em 28 de maio, realizou-se tele-encontro de alto nível sobre financiamento para o desenvolvimento no quadro da pandemia e pós-pandemia. Convocado pelos primeiros ministros do Canadá e da Jamaica e pelo secretário-geral o evento foi ocasião para privilegiar a Agenda 2030 e procurar estimular investimentos de $10 \%$ do PIB mundial para a resposta e a recuperação da Covid-19, em sintonia com os ODS e o Acordo sobre Mudança Climática. Também foram discutidas modalidades de aliviar as dívidas dos países em desenvolvimento, com envolvimento dos credores privados, com vistas a evitar custos maiores para potenciais investidores, bem como para as próprias sociedades. Deve-se registrar que aquele encontro retomou muitos pontos incluídos no documento Debt and Covid-19: a Global Response in Solidarity (UN, 2020d), que havia sido distribuído pelo Secretariado, em 17 de abril.

No âmbito do Conselho Econômico e Social (Ecosoc), realizou-se, em 11 de maio, briefing virtual intitulado Joining Forces: Effective Policy Solutions for Covid-19 Response (Ecosoc, 2020). Convocado pela presidente do Ecosoc, foi oportunidade para que os Estados-membros pudessem ouvir a vice-secretária-geral das Nações Unidas, bem como os secretários executivos da OMS, FAO, OIT, Unctad, Comissão Econômica e Social para Ásia e Pacífico (Escap, em seu acrônimo em inglês) e a alta comissária para Direitos Humanos, Michele Bachelet. Entre os pontos tratados, que incluem alívio da dívida, inequidades econômicas e sociais, a necessidade de perseverar no caminho da Agenda 2030 e do Acordo sobre Mudança Climática, caberia destacar a afirmação de que sistemas de saúde fortalecidos são a melhor resposta para surtos e pandemias. Nesse contexto, a saúde deve ser vista como investimento, não como um custo para a economia.

A resposta das Nações Unidas à Covid-19 envolve todo o sistema. Nunca antes a Organização concentrou sua atenção a um único assunto, que em sua origem sempre fora tratado de maneira lateral. A página web da Organização incluiu a janela Covid-19 response (UN, 2020e). Ao clicar na chamada aparecem 38 resposta, de 38 entidades. Unicef, PNUD, Alto Comissariado de Direitos 
Humanos, OIT, Banco Mundial, FMI, Unctad e a Unido, inter alia, estão presentes naquela página, como seria de esperar. $\mathrm{O}$ curioso é a presença da Agência para Assuntos Espaciais e da Agência Internacional de Energia Atômica, por conta da possibilidade de assistir centenas de laboratórios em todo o mundo no uso de técnica de testagem derivada da tecnologia nuclear (Reverse Transcription-polymerase chain reaction - real time RT-PCR). Ante a ameaça da pandemia todos queriam, e querem, contribuir na elaboração de soluções para os distintos impactos da pandemia no conjunto das complexas relações humanas. Não há precedente na história da Organização para a enorme concentração de esforços para parar a pandemia e reiniciar a economia, que terá de ser outra, diferente, inclusiva e solidária. O Banco Mundial (World Bank, 2020) e o Fundo Monetário Internacional (IMF, 2020) vêm procurando destinar seus recursos na resposta imediata à Covid-19, bem como nos esforços para desafogar as economias.

Como seria de esperar, a $74^{\mathrm{a}}$ sessão da AGNU adotou duas resoluções específicas sobre o assunto: A/RES/74/270, Global solidarity to fight the coronavirus disease 2019 (Covid-19) (Unga, 2020a); e A/RES/74/274, International cooperation to ensure global access to medicines and medical equipment to face Covid-19(Unga, 2020b). Ambas as resoluções ficam aquém do esperado.

A primeira nota a ameaça à saúde humana reconhece que os pobres serão os mais afetados e que os avanços dos ODS até aqui serão perdidos. Propõe o fortalecimento da cooperação internacional com o propósito de conter, mitigar e derrotar a pandemia. A segunda também nota a ameaça à saúde humana e reconhece igualmente que o peso maior recai sobre os menos favorecidos. Mais ambiciosa, propõe que o fortalecimento da cooperação internacional resulte na garantia ao acesso a vacinas e equipamentos médicos necessários para o tratamento da Covid-19.

A questão principal, a do acesso aos produtos necessários para combater a pandemia, não é tratada de maneira desimpedida. Sobre essa questão, por ocasião do lançamento do Patentscope (Wipo, 2020a), buscador de dados contidos em documentos que podem ser úteis para o desenvolvimento de tecnologias relevantes para a pandemia (a plataforma contém mais de 83 milhões patentes e documentos relacionados e está disponível em dez idiomas), o diretor-geral da Organização Mundial de Propriedade Intelectual (Wompi) afirmou que o maior desafio não é o acesso a vacinas, tratamentos ou curas, mas a ausência de produtos aprovados. O diretor-geral reconheceu, naquela ocasião, que pode haver barreiras relacionadas à propriedade intelectual, mas que tanto as legislações nacionais quanto as internacionais conteriam suficientes flexibilidades para atender às demandas de saúde pública. A verdade é que a implementação daquelas flexibilidades nas esferas nacionais são processos complexos e demorados, que não estão à altura das exigências de uma pandemia. Diretamente relacionada com a Covid-19 há 27 patentes concedidas, a grande maioria em mandarim (Wipo, 2020b). 


\section{Resposta da Organização Mundial da Saúde (OMS) e da Organização Pan-Americana da Saúde (Opas)}

No contexto do Regulamento Sanitário Internacional (RSI ou IHR), em 31 de dezembro de 2019, a OMS foi alertada sobre a ocorrência de casos de pneumonia atípica na China. Em 7 de janeiro de 2020, a etiologia dessa nova doença (Doença por Coronavírus de 2019 - Covid-19) foi confirmada como sendo um novo vírus, denominado Sars-CoV-2. Seguindo o estabelecido pelo RSI, o diretor-geral da OMS convocou uma reunião do Comitê de Emergência o qual, em 30 de janeiro, recomendou que declarasse o surto de Covid-19 como um "Emergência de Saúde Pública de Importância Internacional (ESPII)".

Em resposta a essa situação, em 3 de fevereiro de 2020 foi lançado o Plano Estratégico de Preparação e Resposta (SPRP) da OMS (ver adiante) e, em 4 de fevereiro, o secretário-geral da ONU ativou a Política de Gestão de Crises da ONU. Em 12 de fevereiro, a OMS anunciou as Diretrizes de Planejamento Operacional para os Planos de Ação Nacional (Planning Guidelines to Support Country Preparedness and Response) (WHO, 2020c). Em 11 de março, o diretor da OMS declarou que o mundo se encontrava diante de uma pandemia pela Covid-19, ainda que, na prática, todas as atividades relacionadas à situação já estivessem sendo implementadas.

Em 11 e 12 de fevereiro, a OMS realizou um fórum global de pesquisa e inovação para mobilizar ações internacionais em resposta ao novo coronavírus. $\mathrm{O}$ fórum contou com cientistas líderes do tema, representantes de institutos de pesquisa, órgãos públicos de saúde, ministérios da saúde e financiadores de pesquisa, que se comprometeram em colaborar em diversas áreas de pesquisa, incluindo a identificação da origem do vírus, bem como o compartilhamento de amostras biológicas e sequências genéticas para a descrição da história natural da doença e a busca por insumos de prevenção e tratamento, como vacinas e medicamentos.

Um resultado concreto dessa conferência foi o lançamento pela OMS, em 20 de março, do estudo global denominado ensaio clínico Solidariedade (Solidarity) (WHO, 2020d), uma conjugação de esforços mundiais para dar resposta rápida sobre a eficácia de medicamentos no tratamento da Covid-19. Para alcançar o resultado esperado são necessários milhares de pacientes, o que só seria possível, em tempo hábil, por meio da conjugação de esforços de muitos países coordenados pela OMS. No Brasil, essa iniciativa está sendo coordenada pela Fiocruz e o Decit/MS e sendo implementada em 18 hospitais de 12 estados.

Em 14 de abril, a OMS lançou uma atualização do plano estratégico $\left(\mathrm{Co}^{-}\right.$ vid Strategy Update) (WHO, 2020a), que concentra as ações em:

- Mobilizar todos os setores e comunidades para garantir que participem da resposta

- Controlar casos e clusters para prevenir a transmissão comunitária, isolando os casos, tratando e fazendo o rastreamento, a quarentena e o suporte a todos os contatos 
- Suprimir a transmissão comunitária através de distanciamento físico e outras medidas apropriadas como restrições de viagens domésticas e evitar aglomerados

- Reduzir a mortalidade por meio da assistência clínica adequada aos afetados pelo Covid-19

- Desenvolver vacinas e terapêuticas seguras e eficazes e acessíveis.

Para facilitar o intercâmbio de informações e a coordenação de esforços, a OMS lançou a Plataforma de Parceiros Covid-19 (WHO, 2020e), ferramenta para conectar e habilitar a participação coordenada de todos os países, parceiros, doadores e colaboradores da resposta global à Covid-19.

A Rede Global de Alerta e Resposta (Global Outbreak Alert and Response Network (GOARN) lançou um ' $h u b$ ' de conhecimento sobre a Covid-19 (Goarn, 2020), projetado como repositório central de informações de saúde pública com orientação, ferramentas e webinars de alta qualidade, acessados livremente.

A iniciativa Equipes Médicas de Emergência (EMT) (WHO, 2020f) implantou um total de 19 equipes internacionalmente e outras 36 equipes estão apoiando operações nacionais.

Ao nível regional, seguindo o estabelecido no RSI, a Organização Pan-Americana da Saúde (Opas) é responsável por informar e apoiar a implementação regional. Para isso, estabeleceu um comando regional e intensificou as ações de cooperação nos países e territórios da região. A Opas mantém uma plataforma regional (Paho, 2020a) com informações de várias naturezas sobre situação e recursos para o enfrentamento da pandemia.

No dia 24 de abril com a participação de líderes mundiais a OMS lançou uma aliança internacional para acelerar a produção e distribuição de tratamentos a Covid-19 (WHO, 2020b), seguida de uma reunião em 4 de maio, promovida pela presidente da OECD, que conseguiu arrecadar expressivos fundos para apoiar o desenvolvimento de uma vacina e que esteja à disposição em tempo recorde. Essa iniciativa tem contado com a participação e o apoio direto de presidentes (como de França, Alemanha e Costa Rica), da SG das Nações Unidas, Fundação Gates, Gavi, Wellcome, Unitaid e União Africana.

Em 20 de abril, um grupo representativo das associações de saúde pública, academias científicas e autoridades políticas enviou carta ao secretário-geral da ONU sugerindo que se instalasse, na OMS, um grupo de trabalho sobre equidade em saúde, o qual apoiaria as organizações na implementação de medidas de combate à pandemia e, ao mesmo tempo, promovendo a equidade em saúde (Sustainable Health Equity, 2020).

Pela primeira vez na história da organização, a Assembleia Mundial da Saúde (WHO, 2020g) se realizou de forma virtual e aprovou, por unanimidade, uma única resolução, proposta por 135 Estados-membros: a resolução WHA 73.1, intitulada "Resposta à Covid-19" (WHA, 2020), que ressalta pontos essenciais para enfrentar a pandemia e seus muitos efeitos negativos. A Assembleia 
contou com discursos de renovado apoio ao trabalho dedicado da OMS (WHA, 2020) por parte dos Estados-membros e também de diversos chefes de Estado.

A Resolução aprovada expressa a profunda preocupação dos Estados-membros pela morbidade e mortalidade causadas pela pandemia de Covid-19, seus efeitos negativos na saúde física e mental e no bem-estar social, as repercussões negativas na economia e na sociedade, com a consequente exacerbação das desigualdades dentro dos países e entre eles.

Sublinha que é dos governos a responsabilidade primordial pela adoção e aplicação de respostas à pandemia de Covid-19, que sejam específicas para seu contexto nacional, assim como pela mobilização dos recursos necessários para isso.

Recorda o mandato constitucional da OMS de atuar como autoridade reitora e coordenadora em assuntos de saúde internacional, inserida na resposta mais ampla das Nações Unidas, incluindo o reforço da cooperação multilateral. Nesse sentido, cita as já mencionadas resoluções da AGNU (A/RES/74/270 e A/RES/74/274).

Contudo, ao contrário das duas resoluções adotadas pela AGNU sobre a Covid-19, a da AMS (WHA73.1) situa a questão do acesso no quadro de referência do Acordo TRIPS, bem como no da Declaração de Doha sobre TRIPS e Saúde Pública. Com efeito, a resolução dedica três parágrafos operativos àquela questão no quadro de TRIPS: um primeiro, de caráter geral, pede a remoção urgente e injustificada de obstáculos ao acesso, consistente com as determinações de TRIPS e as flexibilidades inscritas na Declaração de Doha; o segundo faz um apelo às organizações internacionais e às partes interessadas para que utilizem repositórios voluntários de licenciamento de patentes (patent pools), consistentes com TRIPS; e o terceiro, dirigido ao diretor-geral, para que identifique e apresente opções, consistentes com TRIPS, que visem garantir o acesso a medicamentos, vacinas e equipamentos médicos.

As seguidas reiterações de consistência com TRIPS parecem dizer que a prioridade reside naquele Acordo e não na situação pandêmica. Compare-se, por exemplo com a resolução A/R/65/95 da AGNU, acima, que enfatiza o direito a usar plenamente as disposições de TRIPS e da Declaração de Doha sobre TRIPS e Saúde Pública.

Nesse período, foram lançadas dúvidas por Estados-membros sobre a atuação da OMS no combate à pandemia. Essa série de acusações e a decisão de cortar o pagamento das cotas e outras contribuições voluntarias à OMS distraíram as ações globais; entretanto estimularam um grande apoio de instituições e países que aumentaram as contribuições à organização. Essa atitude teve repercussão internacional e vários líderes, acadêmicos e representantes da área privada manifestaram seu desacordo com a falta de oportunidade e a motivação dessas manifestações.

Enquanto a pandemia mostrava sinais de controle nos países do Norte, a situação se mostra cada vez mais preocupante na América Latina e África. Apesar 
de exímia atuação e histórico compromisso dos profissionais de saúde e da área social, intensificando as atividades e alertando as autoridades sobre as tendências epidemiológicas futuras, nem sempre esse apelo tem sido ouvido e reverberado. Associadas, as carências dos sistemas de saúde e as enormes desigualdades socioeconômicas e ambientais deixam transparecer um quadro de incertezas e prognósticos sombrios para tais regiões, que têm contado ainda com apoios e intervenções locais, somando orientações globais da OMS e regionais da OPAS e da WHO-AFRO.

Uma preocupação que aos poucos ganha espaço central nas estratégias de resposta é a proteção aos trabalhadores do setor saúde e a proteção das populações mais vulneráveis, como trabalhadores autônomos, do comércio e dos transportes, comunidades indígenas e afrodescendentes, populações economicamente carentes, em situação de rua, encarcerados, e pessoas com mais de 70 anos e grupos de pessoas com algumas pré-condições de enfermidade, como hipertensão, diabetes, obesidade, asma, pacientes com imunossupressão e renais crônicos.

Respostas específicas, de caráter regional e global a esses desafios, foram o lançamento, pela Opas, de um documento sobre a promoção da equidade em saúde, igualdade de gênero e étnica, e direitos humanos, nas respostas do Covid-19 (Paho, 2020b), páginas com conteudo especializado de saúde mental (WHO, 2020h; Opas, 2020) e outras, com orientações aos trabalhadores de saúde (WHO, 2020i).

Para ampliar os esforços em relação ao acesso equitativo e global às tecnologias de combate ao Covid-19, o diretor-geral da OMS e o presidente da Costa Rica, com apoio de mais de 30 países, inclusive o Brasil, lançaram a iniciativa Pool de Acesso à Tecnologia Covid-19 (Covid-19 Technology Access Pool-C-TAP) (WHO, 2020j). A iniciativa busca garantir que os avanços científicos beneficiem a toda a humanidade e sejam disponibilizados como bens públicos globais. Também se constitui em marco para a solidariedade e colaboração globais com base na ciência aberta. Será uma plataforma de compartilhamento de informações que ajudará o acesso equitativo a tecnologias e outras ferramentas para o combate à Covid-19.

A C-TAP é uma iniciativa de participação voluntaria e a OMS a considera como complemento aos planos 'Covid-19 Strategic Preparedness and Response Plan' e ao 'Access to Covid-19 Tools (ACT) Accelerator', já referidos anteriormente, assim como de outras iniciativas semelhantes, relacionadas a apoiar compromissos internacionais, como: o Objetivo de Desenvolvimento Sustentável 3 da Agenda 2030; a Estratégia Global da OMS e o Plano de Ação em Saúde Pública, Inovação e Propriedade Intelectual (GSPA-PHI); o Roteiro da OMS para acesso a medicamentos, vacinas e produtos de saúde 2019-2023; e as resoluções da AGNU já mencionadas.

Os danos à saúde global vão além da Covid-19 em si, como mostram, por exemplo, os resultados de avaliação da OMS sobre serviços de prevenção 
e tratamento de doenças crônicas não-transmissíveis (DCNT), que estão sendo prejudicados durante o período da pandemia: $53 \%$ dos serviços na hipertensão, $49 \%$ na diabetes, $42 \%$ no tratamento de câncer e $31 \%$ nas emergências cardiovasculares.

Tal alteração foi atribuída, inicialmente, ao grande número de remanejamento de funcionários que trabalham na área de DCNT para apoiar a atenção à Covid-19, assim como a escassez de medicamentos, diagnósticos e outras tecnologias. A telemedicina foi utilizada em mais da metade dos países para substituir consultas presenciais e triagem. O impacto desse problema, além de atrasar o cumprimento da meta sobre DCNT da Agenda 2030, deve repercutir em curto e médio prazo em tais doenças, às quais de atribui a mortalidade precoce de 41 milhões de pessoas por ano ( $71 \%$ das mortes em todo o mundo), das quais 15 milhões com idades entre 30 e 69 anos e em países de baixa e média rendas, nos quais ocorrem mais de $85 \%$ das mortes "prematuras".

Em 26 de maio, a OMS lançou o manifesto "Por uma recuperação saudável da Covid-19: Prescrições para uma recuperação saudável e verde da Covid-19". O diretor-geral da OMS, Tedros Adhanom, em discurso dirigido à $73^{\text {a }}$ S, em 18 de maio de 2020, referia que "a pandemia é um lembrete da estreita e delicada relação entre as pessoas e o planeta. Todos os esforços para tornar o mundo mais seguro estão fadados ao fracasso, a menos que abordem a interface crítica entre pessoas e patógenos e a ameaça existencial das mudanças climáticas, que está tornando a Terra menos habitável”.

O manifesto assinala que a Covid-19 é o maior choque global em décadas, com milhares de vidas perdidas, economia mundial em recessão e danos aos sistemas de saúde. Também chama a atenção sobre a importância de manter os compromissos com o desenvolvimento sustentável, já que as reduções de gastos feitos negligenciando a proteção ambiental, a preparação de emergências, os sistemas de saúde e as redes de segurança social, provou ser uma falsa economia e que tem custado muito mais ao mundo o combate a suas consequências como a Covid-19 do que haver feito investimentos na Agenda 2030 e seus ODS. O manifesto pede que as decisões para uma recuperação saudável e verde sigam as seguintes prescrições:

1) Proteger e preservar a natureza como fonte da saúde humana

2) Investir em serviços essenciais: água e saneamento e energia limpa em estabelecimentos de saúde

3) Garantir uma rápida transição energética para alternativas saudáveis

4) Promover sistemas alimentares saudáveis e sustentáveis

5) Construir cidades saudáveis e vivas

6) Eliminar o financiamento da poluição com dinheiro público

Cabe mencionar aqui um episódio relevante no espaço político do multilateralismo global em saúde: o afastamento dos Estados Unidos da OMS, em 
29 de maio de 2020 (Buss; Alcázar, 2020). A pandemia ocorre num momento crítico da disputa sino-americana pela hegemonia política e econômica global que, de forma inesperada e indesejável para o manejo global da pandemia, foi transladada para o âmbito da OMS, instituição reitora do processo de enfrentamento da enfermidade.

Em carta (Trump..., 2020) dirigida ao diretor geral da OMS, em 18/5 (dia em que iniciava a $73^{\mathrm{a}}$ AMS), o presidente americano historiou sua versão sobre a evolução da epidemia, acusando a OMS e a China de estarem em conluio, e ameaçou a organização de tornar permanente o congelamento do repasse das contribuições dos Estados Unidos à organização, iniciado em 14/4, e desfiliar-se da organização, se em 30 dias ela não se comprometesse com "grandes melhorias substantivas", seja lá o que isso poderia significar. Não esperou tanto: desligou-se em 29 de maio, passados apenas 11 dias do envio da carta, tendo também como motivo o desacordo com a Resolução da $73^{a}$ AMS já mencionada.

De fato, as únicas ressalvas à resolução vieram do governo americano (United States of America, 2020). De um lado, "não aceita referências a 'saúde sexual e reprodutiva' ou outra linguagem que sugira ou declare explicitamente que o acesso ao aborto está incluído no fornecimento de serviços de saúde populacionais ou individuais [...]", como supõe que estejam implícitos nos parágrafos operativos 7.5 e 9.4 da Resolução, objeções que não comentaremos por considera-las secundários na mesma. De outro, opõe-se aos três parágrafos sobre o quadro TRIPS, já mencionado acima. Com tais argumentos, os Estados Unidos rompem os laços com a OMS, em decisão muito criticada dentro e fora do país, por organizações multilaterais como a União Europeia e academias de ciências e sociedades médicas americanas e de todo o mundo. A decisão, para ser definitiva, deve ter a aprovação do Congresso americano que, por diversas manifestações subsequentes, deverá se opor à intempestiva decisão do primeiro mandatário dos Estados Unidos.

Embora politicamente tenha sido um desastre, a decisão americana de desligar-se da OMS e suspender sua contribuição, paradoxalmente fez crescer o apoio ao trabalho da organização entre outros atores políticos globais, aqui se incluindo, apenas como exemplos, a União Europeia e seus líderes e países mais destacados, assim como muitas entidades médicas e científicas nacionais americanas e globais.

Nesse sentido, uma nota final: contra as expectativas lógicas de união e apoio mútuo no combate a uma ameaça global como a pandemia, enquanto ainda não havíamos completado este artigo, jornais noticiavam a possível saída do Brasil da OMS, ainda sem confirmação de que se trate de decisão oficial. Entretanto, manter e fortalecer a única instancia de coordenação global em saúde, a OMS, parece ser, sem dúvida, a melhor opção política e técnica, inclusive para o Brasil que, junto com a China, propôs a criação da OMS na Conferência de 
São Francisco, em 1945, e que, ao longo de seus 75 anos, teve voz reconhecida internacionalmente nesse âmbito. Mantendo-se como Estados-membros da OMS, os países podem continuar a contribuir na busca de soluções para todo o espectro de questões da saúde global, para seus determinantes sociais, bem como para os problemas de saúde que hoje se encontram enlaçados com os da política exterior.

\section{Considerações finais}

A pandemia pela Covid-19 desnudou as virtudes e as dificuldades encontradas pelo sistema multilateral no trato de qualquer tema complexo e polêmico no plano global. A pandemia não só eliminou vidas, como trouxe medo e pânico a todos os recantos da terra, como poucas vezes foi visto na história da humanidade. A imensa exposição midiática multiplicou por muitas vezes o medo, mas também gestos de confiança, solidariedade e esperança.

Examinando os muitos documentos relativos à pandemia emanados do sistema das Nações Unidas e sua agência especializada em saúde, a OMS, facilmente se conclui que eles cobrem praticamente todos as dimensões necessárias para o enfrentamento da pandemia pela Covid-19. Em absoluto são documentos perfeitos ou suas resoluções são isentas da retórica que costuma permear textos no qual se requer o malabarismo do consenso, mas tem dado conta do recado, pelo menos parcialmente.

Algumas questões precisam necessariamente ser levantadas nestas reflexões finais. Qual será o papel de um multilateralismo fragilizado e fraturado na reconstrução do mundo pós-pandemia? As discussões sobre a pós-pandemia, que certamente ocorrerão no âmbito multilateral, contribuirão para o mundo "voltar à normalidade" pré-pandêmica? Mas que normalidade? A que nos trouxe até aqui? À normalidade que favorece pandemias, que destrói ecossistemas, que provoca as mudanças climáticas, que gera desigualdades econômicas e sociais que beiram o obsceno e que se baseia em um modelo econômico desumano, insustentável e ecoagressivo?

Enfim, são respostas que apenas o tempo trará. Resta, contudo, a esperança de que os povos do mundo compreendam que sem a genuína e democrática colaboração internacional pouco se avançará, seja na prevenção de processos pandêmicos equivalentes e outras ameaças até mais graves e definitivas como a mudança climática, seja na promoção de um mundo que viva em paz e em maior harmonia política.

\section{Notas}

1 Pequenos surtos locais também ocorreram, à época, em Mali e Nigéria, e casos isolados em Senegal, Gâmbia, Estados Unidos, Itália, Reino Unido e Espanha. Neste último dia 30 de maio de 2020, a República Democrática do Congo informou à OMS sobre o $11^{\circ}$ surto pelo vírus ebola no país desde 1976, o atual, na zona sanitária de Wangata-Mbandaka, província de Équateur, com seis casos e quatro mortes, depois de 
recém-ter controlado um surto da enfermidade no leste do país e de reportar também a coexistência de uma epidemia de sarampo.

2 As outras foram: 25 de abril de 2009 - pandemia de HINl; 5 de maio de 2014 - disseminação internacional de poliovírus; 8 agosto de 2014 - surto de ebola na África Ocidental; 1 de fevereiro de 2016 - vírus zika e aumento de casos de microcefalia e outras malformações congênitas; 18 maio de 2018 - surto de ebola na República Democrática do Congo.

3 Estima-se que a varíola matou cerca de 300 milhões de pessoas, mas ao longo de todos 80 anos em que esteve ativa no mundo; a pandemia de gripe teria matado de 20 a 50 milhões de pessoas em ondas epidêmicas entre os 1910-1920.

\section{Referências}

AGÊNCIA NACIONAL DE VIGILÂNCIA SANTÁRIA (ANVISA). Regulamento Sanitário Internacional - RSI. Brasília: Anvisa, 2005. (Versão em português aprovada pelo Congresso Nacional por meio do Decreto Legislativo 395/2009 publicado no Diário Oficial da União de 10 jul. 9, p.11). Disponível em: <http://portal.anvisa.gov. br/documents/375992/4011173/Regulamento+Sanit\%C3\%Al rio+Internacional. pdf/42356bfl-8b68-424f-b043-ffe0da5fb7e5>. Acesso em: 7 jun. 2020.

BUSS, P. M.; ALCÁZAR, S. Por que Trump rompeu com a OMS? Le Monde Diplomatique Brasil, São Paulo, 8 jun. 2020. Disponível em: <https://diplomatique.org.br/ por-que-trump-rompeu-com-a-oms/>. Acesso em: 8 jun. 2020.

GLOBAL OUTBREAK ALERT AND RESPONSE NETWORK (GOARN). Covid-19 knowledge hub. Disponível em: <https://bit.ly/2Wqlc2T>. Acesso em: 7 jun. 2020.

INTERNATIONAL MONETARY FUND (IMF). Policy responses to Covid-19. Disponível em: <https://www.imf.org/en/Topics/imf-and-covid19/Policy-Responses-to-COVID-19>. Acesso em: 7 jun. 2020.

ORGANIZAÇÃO PAN-AMERICANA DA SAÚdE (OPAS). Ministério da Saúde e OPAS iniciam campanha para promover a saúde mental no contexto da Covid-19. OPAS, 21 abr. 2020. Disponível em: <https://bit.ly/2MCbFE4>. Acesso em: 7 jun. 2020.

PAN AMERICAN HEALTH ORGAZNITATION (PAHO). Covid-19 situation in the region of the Americas. Paho, 2020a. Disponível em: <https://www.paho.org/en/ topics/coronavirus-infections/coronavirus-disease-covid-19>. Acesso em: 7 jun. 2020.

. Promoting health equity, gender and ethnic equality, and human rights in Covid-19 responses: key considerations. Paho, 2020b. Disponível em: <https://bit. ly/3d6L7Gt>. Acesso em: 7 jun. 2020.

SUSTAINABLE HEALTH EQUITY. Global movement for sustainable health equity. Disponível em: <https://www.sustainablehealthequity.org/>. Acesso em: 7 jun. 2020.

THE LANCET. Oslo Ministerial Declaration - global health: a pressing foreign policy issue of our time. The Lancet, v.369, n.9570, p.1373-8, Apr. 2007. Disponível em: <https://www.thelancet.com/journals/lancet/article/PIIS0140-6736(07)60498-X/ fulltext>. Acesso em: 7 jun. 2020.

TRUMP Letter WHO, May 18 2020. Disponível em: <https://apps.npr.org/documents/document.html?id=6895635-TrumpLetterWHO>. Acesso em: 7 jun. 2020. 
UNITED NATIONS (UN). Shared Responsibility, Global Solidarity: responding to the socio-economic impacts of Covid-19. UN, Mar. 2020a. Disponível em: <https:// unsdg.un.org/sites/default/files/2020-03/SG-Report-Socio-Economic-Impact-of-Covid19.pdf>. Acesso em: 7 jun. 2020.

The Secretary-General's UN Covid-19 response and recovery fund. UN, Apr. 2020b. Disponível em: <https://unsdg.un.org/sites/default/files/2020-04/COVID19-Response-Recovery-Fund-Document.pdf>. Acesso em: 7 jun. 2020.

Covid-19 and human rights. We are all in this together. UN, 2020c. Disponível em: <https://www.un.org/sites/un2.un.org/files/un_policy_brief_on_human_rights_and_covid_23_april_2020.pdf>. Acesso em: 7 jun. 2020.

Debt and Covid-19: A Global Response in Solidarity. UN, April 17 2020d. Disponível em: <https://www.un.org/sites/un2.un.org/files/un_policy_brief_on_ debt_relief_and_covid_april_2020.pdf>. Acesso em: 7 jun. 2020.

Coronavirus global health emergency. UN, 2020e. Disponível em: <https://www. un.org/en/coronavirus>. Acesso em: 7 jun. 2020.

UNITED NATIONS ECONOMIC AND SOCIAL COUNCIL (Ecosoc). Joining forces: effective policy solutions for Covid-19 response. Ecosoc, May 11 2020. Disponível em: <https://www.un.org/ecosoc/sites/www.un.org.ecosoc/files/files/ en/2020doc/Summary-COVID19-briefing.pdf>. Acesso em: 7 jun. 2020.

UNITED NATIONS GENERAL ASSEMBLY (Unga). Resolution A/RES/64/265. Prevention and control of non-communicable diseases. UNGA, 2010. Disponível em: <https://undocs.org/en/A/RES/64/265>. Acesso em: 7 jun. 2020.

Resolution A/RES/65/95. Global health and foreign policy. UNGA, 2011. Disponível em: <https://undocs.org/en/A/RES/65/95>. Acesso em: 7 jun. 2020.

Resolution A/RES/69/1. Measures to contain and combat the recent Ebola outbreak in West Africa. UNGA, 2014. Disponível em: <https://undocs.org/en/A/ RES/69/1>. Acesso em: 7 jun. 2020.

Resolution A/70/723. Protecting humanity from future health crises. Report of the High-level Panel on the Global Response to Health Crises. UNGA, 2016 a. Disponível em: <https://www.un.org/ga/search/view_doc.asp?symbol=A/70/723>. Acesso em: 7 jun. 2020.

Resolution A/70/824. Strengthening the global health architecture: implementation of the recommendations of the High-level Panel on the Global Response to Health Crises Report of the Secretary-General. UNGA, 2016b. Disponível em: $<$ https://www.un.org/ga/search/view_doc.asp?symbol=A/70/824>. Acesso em: 7 jun. 2020 .

Resolution A/RES/72/139. Global health and foreign policy: addressing the health of the most vulnerable for an inclusive Society. UNGA, 2018. Disponível em: <https://undocs.org/A/RES/72/139>. Acesso em: 7 jun. 2020.

Resolution A/RES/74/270. Global solidarity to fight the coronavirus disease 2019 (Covid-19). UNGA, 2020a. Disponível em: <https://undocs.org/en/A/ RES $/ 74 / 270>$. Acesso em: 7 jun. 2020.

A/RES/74/274. International cooperation to ensure global access to medi- 
cines, vaccines and medical equipment to face Covid-19. UNGA, 2020b. Disponível em: <https://undocs.org/en/A/RES/74/274>. Acesso em: 7 jun. 2020.

UNITED NATIONS OFFICE FOR THE COORDINATION OF HUMANITARIAN AFFAIRS (Unocha). Global Humanitarian Response Plan Covid-19. Geneva: Unocha, 2020a. Disponível em: <https://www.unocha.org/sites/unocha/files/Global-Humanitarian-Response-Plan-COVID-19.pdf>. Acesso em: 7 jun. 2020.

Achievements of local and international organizations in response to $\mathrm{Co}^{-}$ vid-19. Unocha, 2020b. Disponível em: <https://www.unocha.org/sites/unocha/ files/COVID-19_Response_Achievements.pdf>. Acesso em: 7 jun. 2020.

UNITED STATES OF AMERICA. Departament of State. U.S. explanation of position "Covid-19 response" resolution. Disponível em: <https://geneva.usmission. gov/2020/05/19/explanation-of-position-covid-19-response-resolution/>. Acesso em: 7 jun. 2020 .

WORLD BANK. World Bank Group and Covid-19 (coronavirus). Disponível em: <https://www.worldbank.org/en/who-we-are/news/coronavirus-covid19>. Acesso em: 7 jun. 2020.

WORLD HEALTH ASSEMBLY (WHA). Resolution WHA73.1 Covid-19 response. WHA, 2020. Disponível em: <https://apps.who.int/gb/ebwha/pdf_files/WHA73/ A73_Rl-en.pdf>. Acesso em: 7 jun. 2020.

WORLD HEALTH ORGANIZATION (WHO). Covid-19 strategy update. Geneva: WHO, 2020a. Disponível em: <https://www.who.int/docs/default-source/coronaviruse/covid-strategy-update-14april2020.pdf?sfvrsn=29da3ba0_19>. Acesso em: 7 jun. 2020 .

Access to Covid-19 tools (act) accelerator. WHO, Apr. 24 2020b. Disponível em: <https://www.who.int/publications/m/item/access-to-covid-19-tools-(act)-accelerator $>$. Acesso em: 7 jun. 2020.

Covid-19 strategic preparedness and response plan. Operational planning guidelines to support country preparedness and response. Geneva: WHO, 2020c. Disponível em: <https://www.who.int/docs/default-source/coronaviruse/covid-19-sprp-unct-guidelines.pdf>. Acesso em: 7 jun. 2020.

"Solidarity" clinical trial for Covid-19 treatments. WHO, Jun. 4 2020d. Disponível em: <https://www.who.int/emergencies/diseases/novel-coronavirus-2019/ global-research-on-novel-coronavirus-2019-ncov/solidarity-clinical-trial-for-covid-19-treatments>. Acesso em: 7 jun. 2020.

Covid-19 partners platform. WHO, 2020e. Disponível em: <https://covid-19-response.org/>. Acesso em: 7 jun. 2020.

EMT mission. WHO, 2020f. Disponível em: <https://extranet.who.int/ emt/>. Acesso em: 7 jun. 2020.

Seventy-third World Health Assembly, May 18-19 2020. WHO, 2020g. Disponível em: <https://www.who.int/about/governance/world-health-assembly/ seventy-third-world-health-assembly>. Acesso em: 7 jun. 2020.

. Mental health \& Covid-19. WHO, 2020h. Disponível em: <https://bit. ly/375Nebv>. Acesso em: 7 jun. 2020. 
WORLD HEALTH ORGANIZATION (WHO). Guidance for health workers. WHO, 2020i. Disponível em: <https://bit.ly/30cUqkE>. Acesso em: 7 jun. 2020.

Covid-19 technology access pool. WHO, 2020j. Disponível em: <https:// www.who.int/emergencies/diseases/novel-coronavirus-2019/global-research-on-novel-coronavirus-2019-ncov/covid-19-technology-access-pool>. Acesso em: 7 jun. 2020.

WORLD INTELLECTUAL PROPERTY ORGANIZATION (WIPO). The PATENTSCOPE database provides access to international Patent Cooperation Treaty (PCT) applications in full text format on the day of publication, as well as to patent documents of participating national and regional patent offices. WIPO, 2020a. Disponível em: <https://www.wipo.int/patentscope/en/>. Acesso em: 7 jun. 2020.

. Pesquisa simples. Disponível em: <https://patentscope.wipo.int/search/pt/ result.jsf?_vid=P10-KB6VQF-23678>. WIPO, 2020b. Acesso em: 7 jun. 2020.

RESUMO - O presente artigo analisa, de forma preliminar, as principais posições e respostas de instituições-chave do sistema multilateral das Nações Unidas, como a Assembleia Geral (AGNU) e a Secretaria Geral, e sua agência especializada em saúde, a Organização Mundial da Saúde (OMS), quanto à pandemia pela Covid-19, no período compreendido entre janeiro e maio de 2020. Usando como metodologia a análise de conteúdo dos principais documentos produzidos no âmbito do referido sistema multilateral, identifica a amplitude dessa abordagem, mas também seus limites, assim como os conflitos inerentes a um mundo dividido, que traduzem as disputas de atores políticos relevantes da cena mundial, transferidas também para o campo da saúde global. Ao final, aponta questões fundamentais a serem resolvidas no âmbito de um multilateralismo fraturado e enfraquecido.

PALAVRAS-CHAVE: Pandemia, Covid-19, Multilateralismo, Nações Unidas, Organização Mundial da Saúde.

ABSTRACT - This article makes a preliminary analysis of the main positions and responses to covid-19 of the United Nations system and its main bodies, including the General Assembly, the Secretariat, and the World Health Organization. The article covers the period from January to May, 2020 and uses a methodology based on reading the content of the main documents issued by the UN system, and identifies the scope and limits of the approach taken, the conflicts inherent to a divided world and the disputes of political figures that take their differences to the area of global health. The article closes with a brief consideration of what is to come in a fractured and weakened multilateralism.

KEYWORDS: Pandemic, Covid-19, Multilateralism, United Nations, World Health Organization.

Paulo M. Buss é professor emérito da Fundação Oswaldo Cruz (Fiocruz); diretor do Centro de Relações Internacionais em Saúde da Fiocruz; doutor em Ciências pela Faculdade de Saúde Pública da USP; membro titular da Academia Nacional de Medicina. @ - paulo.buss@fiocruz.br / https://orcid.org/0000-0002-9944-9195. 
Santiago Alcázar é diplomata de carreira do Brasil; pesquisador do Centro de Relações Internacionais em Saúde da Fundação Oswaldo Cruz. @-santiago.alcazar@fiocruz.br / https://orcid.org/0000-0003-2282-0045.

Luiz A. C. Galvão é pesquisador do Centro de Relações Internacionais da Fiocruz; professor adjunto do Departamento de Saúde Internacional da Universidade de Georgetown (EUA). @- luiz.galvao@fiocruz.br / https://orcid.org/0000-0002-3918-0286.

Recebido em 7.6.2020 e aceito em 26.6.2020.

I, II Fundação Oswaldo Cruz, Rio de Janeiro, Brasil.

III Departamento de Saúde Internacional, Universidade de Georgetown, Columbia, Estados Unidos. 